\title{
Gas Chromatography - Mass Spectrometry Determination of Trichothecene Mycotoxins in Commercial Corn Harvested in the State of São Paulo, Brazil
}

\author{
Thaïs V. Milanez ${ }^{*, a}$ and Lúcia M. Valente-Soares ${ }^{b}$ \\ ${ }^{a}$ Seção de Aditivos e Resíduos de Pesticidas, Instituto Adolfo Lutz, Av. Dr. Arnaldo 355, 01246-902 \\ São Paulo-SP, Brazil \\ ${ }^{b}$ Departamento de Ciência de Alimentos, Faculdade de Engenharia de Alimentos, Universidade Estadual de Campinas, \\ CP 6121, 13083-682 Campinas-SP, Brazil
}

\begin{abstract}
Investigou-se a incidência de desoxinivalenol (DON), nivalenol (NIN), diacetoxiscirpenol (DAS) e toxinas T-2 (T2) e HT-2 (HT2) em 80 amostras de milho do estado de São Paulo/ Brasil, coletadas nos silos de duas cooperativas deste estado. As amostras foram extraídas com água/ acetonitrila e purificadas com colunas Mycosep. Após derivatização com anidrido trifluoroacético as amostras foram analisadas por cromatografia gasosa-espectrometria de massas. Os limites de detecção ficaram entre $10 \mathrm{ng} \mathrm{g}^{-1}$ e $40 \mathrm{ng} \mathrm{g}^{-1}$. NIV foi encontrada em 5 amostras e DON e NIV ocorreram simultaneamente numa das amostras. DAS, T2 e HT2 não foram detectadas. Este é o primeiro relato que mostra a prevalência de NIV sobre DON em milho do Brasil.
\end{abstract}

The incidence of deoxynivalenol (DON), nivalenol (NIV), diacetoxyscirpenol (DAS), and toxins T-2 (T2) and HT-2 (HT2) in 80 samples of commercial corn harvested in the state of São Paulo, Brazil. They were collected in the silos of the two largest corn farmer's cooperatives of this state. The samples were extracted with water/acetonitrile and cleaned-up with MycoSep columns. After trifluoroacetic anhydride derivatization the samples were submitted to gas chromatography-mass spectrometry. Detection limits ranged from $10 \mathrm{ng} \mathrm{g}^{-1}$ to $40 \mathrm{ng} \mathrm{g}^{-1}$. NIV was present in 5 samples and DON and NIV occurred simultaneously in one sample. DAS, T2 and HT2 were not detected. This is the first report that shows the prevalence of NIV over DON in corn harvested in Brazil.

Keywords: corn, GC-MS, trichothecenes, deoxynivalenol, nivalenol

\section{Introduction}

Trichothecenes constitute a group of toxic substances produced mainly by Fusarium among several different fungal genera. ${ }^{1}$ These compounds have in common the presence of the system 12,13 - epoxy-trichotec-9-en in their structures. ${ }^{2,3}$ Diacetoxyscirpenol (DAS) and the toxins T2 (T2) and HT2 (HT2), deoxynivalenol (DON) and nivalenol (NIV) are among the trichothecenes with greater natural occurrence in food and feed. ${ }^{4-6}$

The ingestion of feed contaminated with trichothecenes has been shown to be toxic and to cause feed refusal, emesis, diarrhea, anorexia, hematological and immunological alterations and even death. Similar symptoms have been observed in humans exposed to trichothecenes. ${ }^{1,2,4,7}$

*e-mail: thaismil@uol.com.br
Trichothecenes occur in cereals worldwide ${ }^{6}$ and contamination in corn is frequently reported ${ }^{8-15}$ There is little information about corn cultivated in Brazil. Prado et $a l .{ }^{16}$ found DON in about $6 \%$ of post-harvested corn samples with levels ranging from 102 to $542 \mathrm{ng} \mathrm{g}^{-1}$ in contaminated samples and $104 \mathrm{ng} \mathrm{g}^{-1} \mathrm{~T} 2$ in one sample. Oliveira et al. ${ }^{17}$ reported the presence of DON in $6 \%$ of samples of popcorn in levels ranging from 30 to $770 \mathrm{ng} \mathrm{g}^{-1}$.

Several methods are used to determine trichothecenes, such as thin layer chromatography, liquid chromatography, gas chromatography, and immunoassays. ${ }^{7,18,19}$ More recently some methods have been developed using the liquid chromatography/tandem mass spectrometry for identification and determination of trichothecenes type A and B..$^{20,21}$ Despite of this, GC-MS is specially appropriate for its capability for simultaneous detection of trichothecenes from the groups A and B and for providing unequivocal identification. ${ }^{22}$ 
In Brazil two crops of corn are planted a year. The main crop is harvested from December to February and its grain volume is three times of the secondary crop harvested from July to September. The main goal of the present work was to evaluate the incidence of the trichothecenes DON, NIV, DAS, T2 and HT2 in commercial corn cultivated in the state of São Paulo, one of the main producers of the cereal in Brazil. In order to achieve this goal the two main farmers cooperatives within the state were sampled during both crops in the period of a year.

\section{Experimental}

\section{Sampling}

A total of 80 samples of commercial corn (Zea mays) harvested in the state of São Paulo, Brazil, were collected in the two largest corn farmers co-operatives within the state of São Paulo. One of them, COOP, located in the area of Paranapanema (west of the state) and another, CAROL, in the area of Mogiana (north of the state). Forty samples were collected from the silos of each cooperative, half from the main crop (December 2001 to February 2002) and half from the secondary crop (July to September/ 2002). Bulk samples from the 2001/2002 harvest (main crop) were collected from the silos. Bulk samples from the 2002 harvest (secondary crop) were collected during the filling of the silos. In both cases sub-samples of $1 \mathrm{~kg}$ were delivered to the laboratory. The samples were ground to pass through a 16-mesh sieve. All the samples were kept in double plastic bags at $-18{ }^{\circ} \mathrm{C}$ until analysis.

\section{Chemicals}

The trichothecene standards DON, NIV, DAS, HT2 and $\mathrm{T}-2$ were purchased from Sigma (USA). The stock solutions of $100 \mu \mathrm{g} \mathrm{mL}^{-1}$ and $1 \mu \mathrm{g} \mathrm{mL}^{-1}$ were prepared with acetonitrile HPLC grade for DON and NIV and in methanol HPLC grade for DAS, HT2 e T2. All solutions were stored at $-18{ }^{\circ} \mathrm{C}$ when not in use. The $\alpha$-chloralose (internal standard) and trifluoroacetic anhydride (TFAA) were from Sigma (USA).

The Mycosep 227 clean-up columns which contain various adsorbents, such as charcoal, Celite and aluminium oxide, were purchased from Romer Labs, Inc. (USA).

\section{GC/MS conditions}

A GC-MS Finnigan MAT (USA) GCQ system with ion trap detector was used for quantification and confirmation of trichothecenes. The electron impact (EI) mode $(70 \mathrm{eV})$ was employed. GC conditions: fused-silica column Restek
Rtx-5MS, 30m x $0.25 \mathrm{~mm}, 0.25 \mu \mathrm{m}$ film (USA); injection port: $260^{\circ} \mathrm{C}$, splitless injection ( $1 \mathrm{~min}$ ), oven: $80^{\circ} \mathrm{C}$ for 0.2 min, $22^{\circ} \mathrm{C} \mathrm{min}-1$ to $205^{\circ} \mathrm{C}$, hold for $0.25 \mathrm{~min}, 2^{\circ} \mathrm{C} \mathrm{min}^{-1}$ to $270{ }^{\circ} \mathrm{C}$. He-flow $1.0 \mathrm{~mL} \mathrm{~min}{ }^{-1}$, Air Liquid do Brazil (São Paulo,BR). Injection volume: $1 \mu \mathrm{L}$ Transfer line: $275^{\circ} \mathrm{C}$, ion source temperature: $200^{\circ} \mathrm{C}$. The data system used was Xcalibur 1.1 (USA). Full scan data were monitored and multiple ion chromatograms were built for quantification using the most characteristics ions $m / z: 81,109,223,251$ and 319 for $\alpha$-chloralose, 117, 145, 231, 259, 584 for DON, 229, 257, 359, 371, 696 for NIV, 91, 124, 229, 329, 402 for DAS, 121, 138, 180, 341, 455 for HT2 and 121, 138, 180, 227,327 and 401 for T2. Identity confirmation was based on retention time, mass spectra and the ratio between characteristic fragments (Table 1).

Table 1. GC-MS of trichothecenes as trifluoroacetyl derivatives (EI mode)

\begin{tabular}{lccc}
\hline Toxin & $\begin{array}{c}\text { Retention time } \\
(\mathrm{min})\end{array}$ & $\begin{array}{c}\text { Mass fragments } \\
(\mathrm{m} / z, \mathrm{Da})\end{array}$ & $\begin{array}{c}\text { Ratio } \\
\text { of intensities }\end{array}$ \\
\hline Nivalenol & about 7.5 & 229 & 2 \\
& & 257 & 1 \\
Deoxynivalenol & about 8.7 & 359 & $1-2$ \\
& & 145 & 3 \\
Diacetoxyscirpenol & about 14.2 & 259 & $2-4$ \\
& & 373 & 1 \\
Toxin HT-2 & & 229 & 1 \\
& about 17.4 & 329 & 1 \\
& & 121 & $2-3$ \\
Toxin T-2 & & 341 & $5-7$ \\
& & 455 & 1 \\
& about 23.5 & 180 & $2-3$ \\
& & 227 & $3-5$ \\
& & 327 & $1-2$ \\
& & 401 & $1-2$ \\
\hline
\end{tabular}

\section{Extraction and cleanup}

Twenty-five grams of ground sample were extracted with $100 \mathrm{~mL}$ acetonitrile-water $(84: 16 \mathrm{v} / \mathrm{v})$ for $5 \mathrm{~min}$ in a highspeed blender. An aliquot of $8 \mathrm{~mL}$ of the extract was transferred into a glass test tube and purified by pushing the Mycosep 227 column. The packing material of Mycosep column is housed in a plastic tube between filter discs. When the column was inserted into the tube, the extract was forced through the packing material of the column. On the top of the plastic tube appeared the cleaned extract. Four $\mathrm{mL}$ of this extract was transferred to a vial and evaporated to dryness under a stream of nitrogen at $60{ }^{\circ} \mathrm{C}$.

\section{Derivatization}

Derivatization was based on Schwadorf and Müller ${ }^{22}$ and Schollenberger et al ${ }^{23}$ After the $\alpha$-chloralose (internal 
standard) addition to the extract followed by evaporation, the residue was dissolved with $1 \mathrm{~mL}$ of methanol, sonicated for $1 \mathrm{~min}$, and then evaporated at $60{ }^{\circ} \mathrm{C}$ under nitrogen. To the dried residue $200 \mu \mathrm{L}$ of TFAA and about 10 to $30 \mathrm{mg}$ sodium bicarbonate $\left(\mathrm{NaHCO}_{3}\right)$ were added. The vial was well closed with Teflon-lined screw-cap and left at $80{ }^{\circ} \mathrm{C}$ for $30 \mathrm{~min}$. After cooling, the mixture was evaporated to dryness under nitrogen. The residue was taken up with 100 $\mu \mathrm{L}$ toluene and sonicated for $1 \mathrm{~min}$ after manual mixing. To remove the excess of reagents $500 \mu \mathrm{L}$ water were added followed by soft manual mixing. The layers were allowed to separate and toluene phase was transferred to a cleaned and dried $4 \mathrm{~mL}$ vial using a Pasteur pipette. Anhydrous $\mathrm{Na}_{2} \mathrm{SO}_{4}$ was added to the toluene followed by a brief mixing. The toluene layer was transferred to a $600 \mu \mathrm{L}$ vial capped with Teflon-faced septum. Sample volumes of $1 \mu \mathrm{L}$ were injected into the GC-MS.

\section{Results and Discussion}

\section{Analytical quality control}

Calibration curves with internal standard were linear from 0.8 to $10 \mathrm{ng} \mu \mathrm{L}^{-1}$ for DON and NIV, from 0.8 to 6.0 ng $\mu \mathrm{L}^{-1}$ for DAS, from 0.8 to $20.0 \mathrm{ng} \mu \mathrm{L}^{-1}$ to $\mathrm{T} 2$ and from 0.8 to $35.0 \mathrm{ng} \mu \mathrm{L}^{-1}$ for HT2. Limits of detection (LOD) and limits of quantification (LOQ) are shown in Table 2. The quantification limits were calculated as being 15 times the values of relative standard deviations ${ }^{24}$ and inside the linearity of the calibration curve.

Mean recovery values were $86 \%$ for DON, $85 \%$ for NIV, $102 \%$ for DAS, $89 \%$ for HT2 and $71 \%$ for T2.
Occurrence of DON, NIV, DAS, HT2 and T2 in corn

NIV has been detected in 8 of 20 samples from the main harvest of CAROL (2001/2002). All of them had NIV in levels below LOQ, considered here as trace. Only one sample of the 20 samples from COOP main harvest (2001/2002) contained traces of NIV.

None of the studied trichothecenes were detected in the 20 samples from CAROL secondary harvest (2002). But the samples coming from COOP secondary harvest had DON and NIV. Seven samples presented NIV at noise level (LOD). It was possible to observe three to four mass fragments characteristics of NIV, among them the molecular ion $(\mathrm{m} / \mathrm{z}=$ 696) always present. Four samples showed traces of NIV (between LOD and LOQ). One sample contained traces of DON, two samples presented NIV at the levels of traces and $106 \mathrm{ng} \mathrm{g}^{-1}$, and one had $71 \mathrm{ng} \mathrm{g}^{-1}$ DON and traces of NIV.

Altogether 16 of the 80 samples analyzed were contaminated with NIV and 2 samples with DON in levels above the limit of quantification. Fifteen per cent of the samples showed traces of NIV and DON. DAS, HT-2, and $\mathrm{T} 2$ were not observed.

Summarizing, 16 (20\%) from a total 80 of samples analyzed were contaminated with NIV and two samples (2.5\%) with DON. In the case of DON the values were above the limit of quantification. The overall levels for both toxins were small and due to co-contamination only $15 \%$ of the samples presented NIV and DON, and of these $6 \%$ were contaminated with NIV. No DAS, HT2 and T2 were detected in the samples.

Figure 1 shows a gas chromatogram of a corn sample naturally contaminated with NIV. Figure 2 presents a
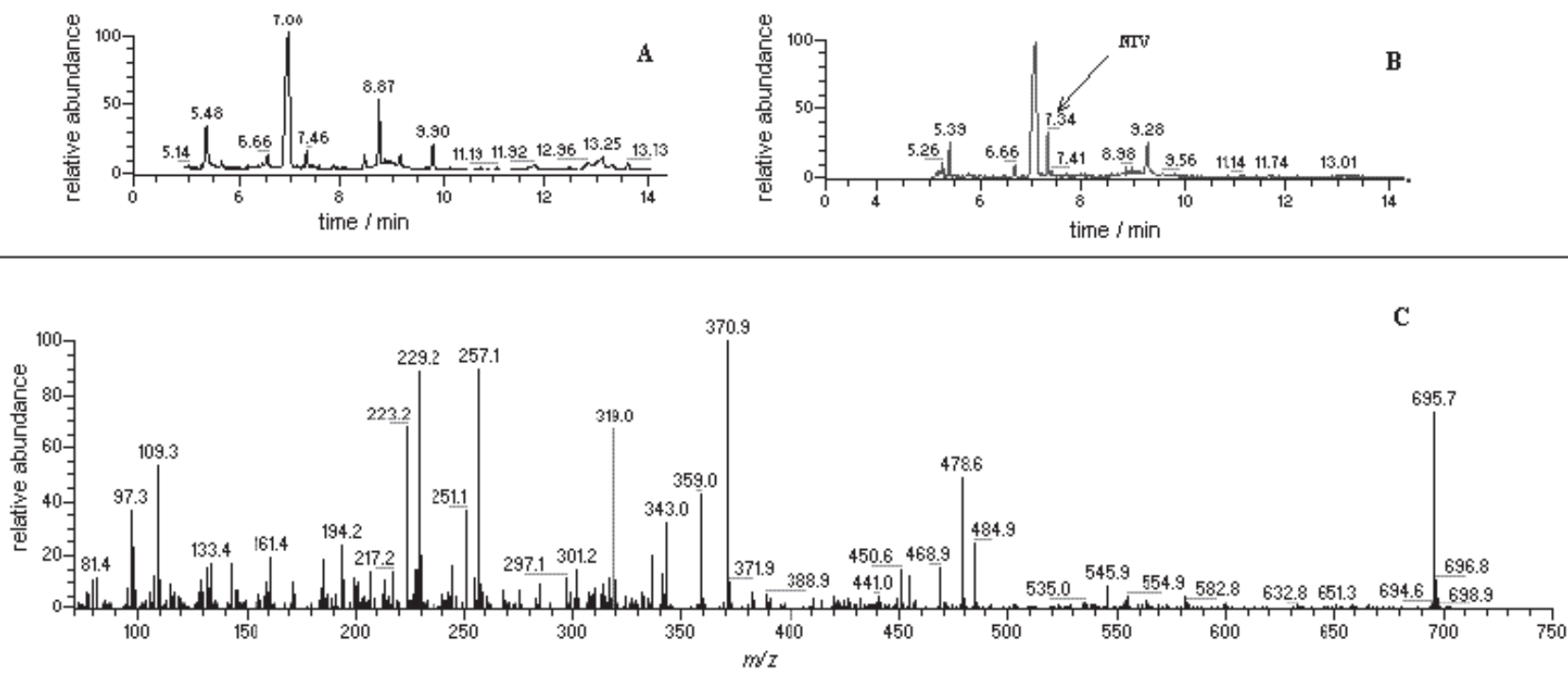

Figure 1. Corn sample containing nivalenol: (A) chromatogram of trifluoroacetyl derivatives; (B) chromatogram (A) rebuilt with the characteristic mass fragments of nivalenol; (C) mass spectrum of nivalenol trifluoroacetyl derivative. Chromatographic conditions in experimental. 

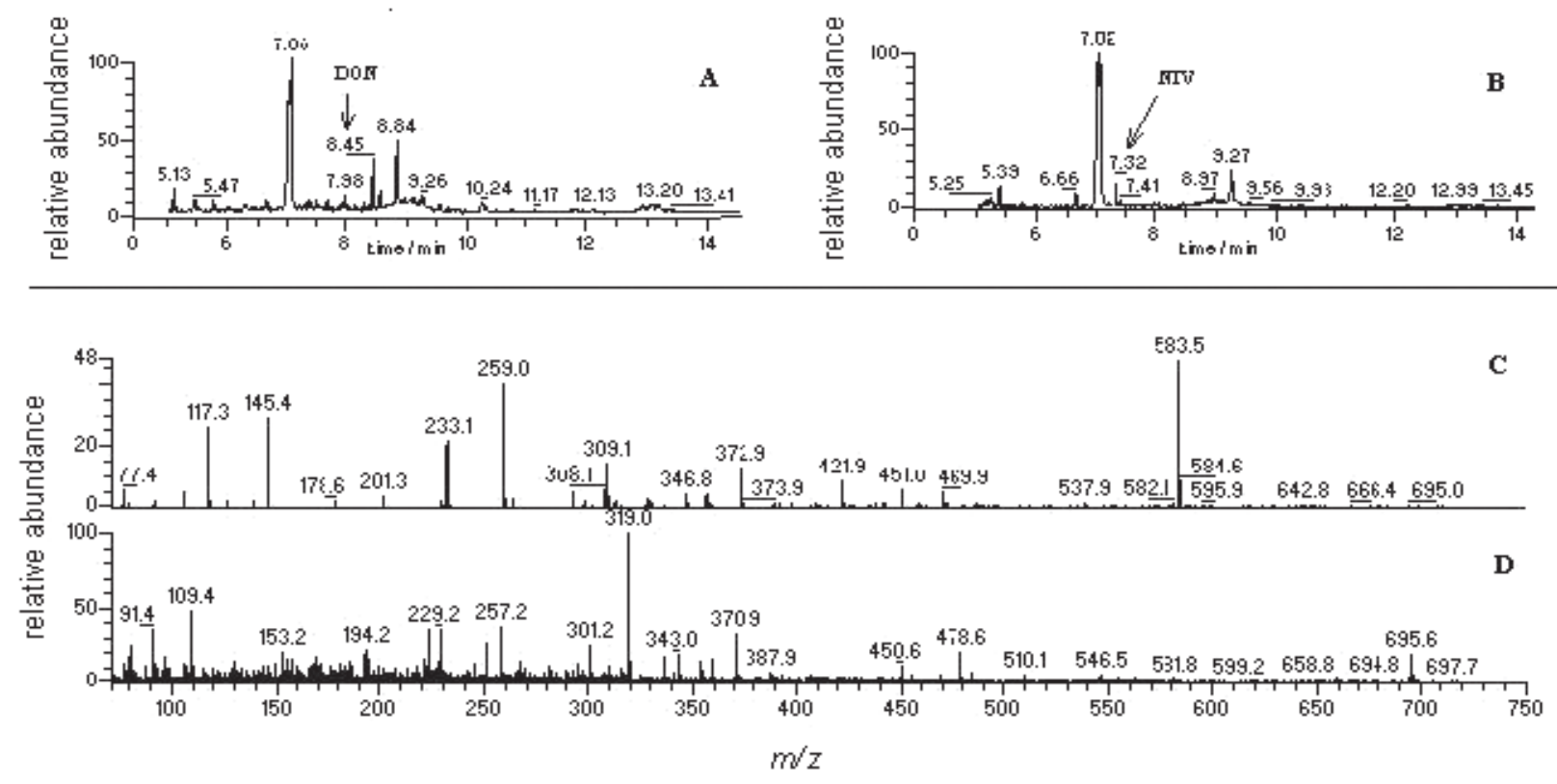

Figure 2. Chromatogram of tryfluoroacetyl derivatives of a corn sample contaminated with deoxynivalenol and nivalenol (A). Chromatogram rebuilt with most characteristics mass fragments for deoxynivalenol and nivalenol trifluoroacetyl derivatives (B). Mass spectrum of deoxynivalenol, trifluoroacetyl derivative (C). Mass spectra of nivalenol, trifluoroacetyl derivative (D). Chromatographic conditions in experimental.

gas chromatogram of a corn sample naturally contaminated with NIV and DON and also their respective mass spectra. The amount of DON and NIV found in these samples were low but it is possible to observe DON characteristic mass spectra and even its molecular ion $(\mathrm{m} / z=584)$. The same happens for NIV (molecular ion $m / z=696$ ).

It is interesting to note the prevalence of NIV over DON. According to Miller ${ }^{25}$ the NIV producing strains are present in some areas of Japan, Australia and Asia and probably rare in North America since DON prevails there over NIV. No surveys are known of NIV in South America. The studies of NIV toxicity are still scarce, but the data available indicate that its toxicity may be greater than $\mathrm{DON}^{4,19}$ and that it may be as toxic as $\mathrm{T} 2$ toxin which is considered one of the most toxic of the trichothecenes. ${ }^{1}$

Table 2. Limits of detection and of quantification of trifluoroacetyl derivatives of DON, NIV, DAS, T2 e HT2, determined in corn by GC-MS

\begin{tabular}{lcc}
\hline Trichothecenes & $\begin{array}{c}\text { Limit of } \\
\text { detection }\left(\mathrm{ng} \mathrm{g}^{-1}\right)\end{array}$ & $\begin{array}{c}\text { Limit of } \\
\text { quantification }\left(\mathrm{ng} \mathrm{g}^{-1}\right)\end{array}$ \\
\hline Deoxynivalenol & 20 & 90 \\
Nivalenol & 10 & 80 \\
Diacetoxyscirpenol & 40 & 180 \\
Toxin HT-2 & 40 & 200 \\
Toxin T-2 & 20 & 70
\end{tabular}

LOD = limit of detection; $\mathrm{LOQ}=$ limit of quantification.

\section{Conclusions}

The levels of DON and NIV found in the corn samples from the state of São Paulo were small and indicated the prevalence of NIV over DON. NIV was detected in $20 \%$ of the samples analyzed. This finding suggests that this commodity should be monitored since the present refers only to the crop of 2001/2002 and the occurrence of the mycotoxins can change due to climate conditions from year to year. The prevalence of occurrence of NIV over DON was so far unsuspected in South America.

\section{Acknowledgments}

This study was financially supported by FAPESP (Proc. $n^{\circ}$ 99/05069-0).

\section{References}

1. Ueno, Y. In Development in Food Science; Ueno, Y., ed.; Elsevier Press: Tokyo, 1983, vol. 4.

2. IARC. International Agency for Research on Cancer. Toxins Derived From Fusarium Graminearum, F. Culmorum and F. Crookwellense: Zearalenone, Deoxynivalenol, Nivalenol and Fusarenone X. In: IARC Monographs on the Evaluation of Carcinogenic Risks to Human; Some Naturally Occurring Substances; Food Items and Constituents, Heterocyclic Aromatic Amines and Mycotoxins. IARC: Lyon, 1993, p 467-488. 
3. Sharma, R.P.; Kim, Y.-W. In Mycotoxins and Phytoalexins; Sharma, R. P.; Salunkhe, D.K., eds.; CRC Press Inc.: Boca Raton, 1991, ch. 13.

4. Ciegler, A.; J. Food Prot. 1978, 41, 399.

5. Scott, P.M.; Food Addit. Contam. 1997, 14, 333.

6. Tanaka, T.; Hasegawa, A.; Yamamoto, S.; Lee, U.S.; Sugiura,Y; Ueno, Y.; J Agric. Food Chem. 1988, 36, 979.

7. Snyder, A. P.; J. Food Prot. 1986, 49, 544.

8. Abbas, H.K.; Mirocha, C.J.; Tuite, J.; Appl. Environ. Microbiol. 1986, 51,841 .

9. Chulze,S.; Bertinetti, C.; Dalcero, A.; Etcheverry, M.; Farnochi, C.; Torres, A.; Rizzo,I.; Varsavsky, E.; Mycot. Res. 1989, 5, 9.

10. Kim, J-C; Kang, H-J; Lee, D-H; Lee, Y-W; Yoshizawa, T.; Appl. Environ. Microbiol. 1993, 59, 3798.

11. Lauren, D.R.; Agnew, M.P.; Smith, W. A.; Sayers, S.T.; Food Addit. Contam. 1991, 8, 599.

12. Luo, Y.; Yoshizawa, T.; Zhang, S-Y.; Zhang, B-J. Mycot. Res., 1992, 8,85 .

13. Okoye, Z.S.C.; Food Addit. Contam. 1992, 10, 631.

14. Park, J.J.; Smalley, E.B.; Chu, F.S.; Appl. Environ. Microbiol. 1996, 62, 1642.

15. Yamashita, A.; Yoshizawa, T.; Aiura, Y.; Sanchez, P.C.; Dizon, E.I.; Arim, R.H.; Sardjone; Biosci. Biotechnol. Bioch. 1995, 59,1804 .
16. Prado, G.; Oliveira, M.S.; Ferreira, S.O.; Corrêa, T.B.S.; Affonso, B.R.R.; Ciênc. Tecnol. Alim. 1997, 17, 259.

17. Oliveira, A.Q.; Soares, L. M.V.; Sawazaki, E.; Ciênc.Tecnol. Alim. 2001, 21, 330.

18. Scott, P.M.; J. Assoc. Off. Anal. Chem. 1982, 65, 876.

19. WHO. World Health Organization, Selected Mycotoxins: Ochratoxins, Trichothecenes, Ergot, Environmental and Health Criteria 105. IPCS (International Programme on Chemical Safety): Geneva, 1990, ch.2, p 71.

20. Biselli, S.; Hummet, C.; Food Addit. Contam. 2005, 22, 752.

21. Laganà, A.; Curini, R.; D’ascenzo, G.; De Leva, I.; Faberi, A.; Pastorini, E.; Rapid Commun. Mass Spectrom. 2005, 19, 2085.

22. Schwadorf, K.; Muller, H.-M.; Chromatographia 1991, 32, 137.

23. Schollenberger, M.; Lauber,U.; Terry Jara, H.; Suchy, S.; Drochner, W. ; Muller, H.-M.; J. Chromatogr. A 1998, 815, 123.

24. Taylor, J.K.; Quality Assurance of Chemical Measurements, $2^{\text {nd }}$ ed., Lewis Publishers: Chelsea, 1987.

25. Miller, J.D.; J. Stored Prod. Res. 1995, 31, 1.

Received: June 24, 2005

Published on the web: February 22, 2006

FAPESP helped in meeting the publication costs of this article. 